\title{
Consumer Willingness to Pay for the Alternative Energy Sources in Pakistan
}

\author{
Mahmuna Ifat ${ }^{1 *}$, Burcu Adiguzel Mercangoz ${ }^{2}$ and Huang Hui ${ }^{3}$ \\ 1. Department of Economics, Sabanci University Istanbul, Istanbul, Turkey. \\ 2. Faculty of Transportation and Logistics, Istanbul University, Istanbul, Turkey. \\ 3. Department of Finance, Qilu University of Technology, Jinan, China.
}

\begin{abstract}
Consistent and inexpensive energy access is pivotal for human development and sustainable living standard. Pakistan is facing a huge gap in the demand and supply of energy which is brewing since 2007. This study analysed the factor influencing the households' willingness to pay (WTP) for the alternative energy source. Using World Bank data, collected from 8500 households, the study presented the findings of the ordered logit model. The results indicate that there exists a positive WTP for energy alternatives for socio-economic characteristics and energy attributes. Besides, it indicates the affordability and cost-saving factor of potential alternative significantly influence the WTP for the alternative energy source. It is suggested for the policymakers to make policies to encourage the invention of the affordable energy products that result in reliable and long-running energy alternatives. Similarly, financial assistance in the form of easily accessible loans, subsidies, and attractive instalments for energy products.
\end{abstract}

Keywords: Energy Poverty, Alternative Energy, Willingness to Pay, Energy Deficit, Household, Ordered Logit Model.

\section{Introduction}

Electricity is a major part of the energy used in residents for everyday life. It is becoming increasingly important for the consumer to be served with better power quality and reliable utility with the increasing consumption of energy worldwide. It is specifically crucial for households in developing countries to access a reliable energy source. It enables them to fulfil their everyday need of energy for cooking, lighting, cooling, and heating of the dwelling (Louw, Conradie, Howells and Dekenah, 2008). It is also essential for the economic growth and sustainable life standard in the country.

In any country, it is increasingly important for the consumers, regulators, and distributors to ensure access to energy to all the residents. To fill the energy deficit gap, beside other measures like a market failure, energy supply, and energy theft, there is a need to come up with the energy alternatives, where the alternative energy refers to such energy source that will ensure access to the energy for energy-deprived households and reliable supply of energy to the households that suffer from the outages. In this way, the alternative energy source is defined as the energy source that is expected to fill the gap between the energy demand and the supply. Hence, the adoption of an alternative energy would fulfil the energy needs during the frequent power outages in the residence. 
Worldwide authorities are utilizing multiple energy resources including solar power, wind, nuclear, hydroelectric, geothermal power, biomass, biofuels, and natural gas to fulfil the energy demand. There is a general shift in energy generation alternatives mainly because of climate issues and an increase in energy demand. The climate issue arises due to the environmental awareness, the environment sensitive consumers and governments shift to more eco-friendly energy generation projects like deployment of solar energy panels, installation of wind turbines (Borchers et al., 2007; Scarpa and Wills, 2010). On the other hand, there are several consumers whose demand for alternative energy sources is driven by the need to access energy (International Finance Corporation [IFC], 2017). The energy deficit issue in many developing countries that causes the energy outages and deprives the access to energy. Hence in such countries, consumers tend towards energy alternatives. These alternatives are helpful for households to complete energy needs. Such alternatives are also significant for the residences in the remote area, where it is expensive to provide the grid connection.

Unfortunately, in Pakistan more than 212 million people across the country lack access to the sustainable and reliable supply of energy, either because they are deprived of the access to the grid or they suffer daily power shortages of 12-16 hours (International Finance Corporation [IFC], 2017). Raising energy demand and lack of energy generation projects has resulted in a huge gap in energy demand and supply. A deficit in the energy supply is brewing since 2007 (Sher et al., 2014). The energy statistics in 2015 showed the electricity demand at 22,158MW in the country, while the installed capacity is $18,000 \mathrm{MW}$, which resulted in a $5000-7000 \mathrm{MW}$ shortfall per day. At the beginning of 2005 national power had a surplus of $1,230 \mathrm{MW}$. In just a few years in 2005, it turns into a shortage of 5,885MW (Government of Pakistan [GOP], 2013). In this scenario, both grids connected, and non-grid connected households are restrained from reliable access to the electricity. As the non-grid connected deprived of regular energy supply and grid-connected households facing energy shortfall 12-16 hours per day (IFC, 2017). Due to the highly irregular supply of energy, the households are deploying a mix of energy alternatives at their resident. (IFC, 2017).

There is a huge potential of alternative energy units in Pakistan both at the household and community level. Despite the brewing energy crises in the country, there is a potential of 2,900,000MW from solar energy sources, 346,000 MW for wind, 3,000MW for biogas, 2,000MW for micro-hydropower and 1,000MW for waste-to-energy (Wakeel et al., 2016). These sources can provide more than enough energy to fulfil the gap (Rafique and Rehman, 2017). However, currently, the share of renewable sources is far below these numbers. However, it is the focus of the government to shift towards efficient and cheaper energy generation projects to reduce the energy demand and supply gap. In the literature (Urpelainen and Yoon, 2015; Shi, Zhou and Kristrom, 2013; Mozumder, Vasquex, and Maratha, 2011; Sardianou and Genoudi, 2013; Theodoropoulou and Karytsas, 2014; Bigerna and Polinori, 2015) the decision regarding adoption of alternative energy source is based upon several factors including demographic factors, economic conditions, energy attributes, knowledge, awareness, and behavioural characteristics.

Pakistan is suffering severely from brewing energy poverty but still, there is very little emphasis on the conceptual and methodological studies related to the issue. All the existing academic work has used limited data. Most of them explored the descriptive statistics derived using data set from a small survey. Moreover, these studies empirically analyse a survey from a small to moderate range of areas. Hence an exploratory investigation is absent based on largescale micro-level household data. As a result, policymakers also had to rely on limited scale 
data literature. It restrains policymakers from the standard literature. However, this study aims to provide large-scale household data based exploratory analysis based on empirical investigation. Moreover, the data used in the study is most comprehensive and detailed to this date. The study also contributes to the energy poverty alleviation literature over a geographically larger area.

There is a growing number of researches on the energy financial issues centred on the consumer's energy burden. In this study it is tried to provide the financial contribution consumers can make to mitigate the energy access problem and ensure the supply of reliable energy. This paper empirically analyses the factors that affect the household's willingness to pay to access the alternative energy. The study employed an ordered logit model. The detailed information about the factor affecting the household's willingness to pay for the energy alternative is important to effectively shape the energy policy. The relevant authorities face investment in the energy sector as the main hurdle in making the availability of energy. In such situations, the investment from consumers is regarded as a part of the solution for the reliable supply of energy. To ensure the reliable energy supply the households in Pakistan deploy a mix of energy technologies at their residents, which enhances an investment in the energy alternatives in many households in Pakistan. These monetary investments are driven by an array of various factors including household socio-economic characteristics, energy attributes, and the potential key factors of the alternative source

The study contributes to the literature on the importance of household attributes and the type of energy sources in determining the willingness to pay for alternative energy. Furthermore, it highlights features such as health, affordability, and cost-saving which affect the household's willingness to pay (WTP) for alternative energy. Henceforth residents are willing to pay for such alternatives which are safer from health hazards. This study implied that the government needs to enhance the research for healthy, affordable, and cost-saving energy alternatives. Hence, it is essential to introduce such policies which ensure the health standards of energy alternative products. Furthermore, there is a need for more research in the field of cost-saving and affordable alternatives. One suggestion is the financial assistance in the form of easily accessible loans, subsidies, and attractive instalments for the energy products. The empirical analysis also sheds light on the importance of peers' effect in the WTP for an alternative. It has implications on the private sector's investment decisions in the alternative energy product market. Hence, this information's led the policymakers towards a more shaped energy policy to combat energy crises.

\section{Research Methodology}

\subsection{Methods}

In this study, the ordered logit model is used to estimate the empirical outcome. In the data, the dependent variable is categorical. The survey questionnaire collected categorical data, ranging from 1-5 regarding how much financial burden households can bear to install an alternative to access the energy and ensure reliable energy supply. The ordered logit model is based on the following linear relationship.

$$
\mathrm{y}_{\mathrm{i}}^{*}=\mathrm{x}_{\mathrm{i}} \beta+\mu_{\mathrm{i}}
$$

where $\beta$ denotes a coefficients vector and $\mathrm{x}$ is a vector of explanatory variables. Whereas $\mathrm{y}_{\mathrm{i}}^{*}$ is the ranking of the households regarding how much financial burden they are willing to bear for 
the access to an alternative energy source.

The logit regression is used when the dependent variable is categorical. The survey questionnaire investigates the willingness to pay of the respondents in the categorical form. The household was asked to respond about the category regarding the amount they would like to pay if they will be fulfilled the energy demand through an alternative source. A response is ranked as 6 if the household showed their interest to bear a financial burden greater than $4 \$$ for the alternative energy source, $\mathrm{y}_{\mathrm{i}}{ }^{*}=5$ for $3-3.99 \$$, and so on until $\mathrm{y}_{\mathrm{i}}{ }^{*}=1$ if household indicates no interest in bearing any further financial burden. The ordered logit model analyses ordered response, where it observe the order for the dependent variable. The model is constructed around a latent regression of the following form:

$$
y^{*}=x^{T} \beta+\varepsilon
$$

where $\mathrm{x}$ denotes the vector of the explanatory variables affecting the WTP, $\beta$ is a vector of coefficients, $\mathcal{E}$ is the error term and $y^{*}$ is the unobserved dependent variable. Instead of $y^{*}$ following categories are observed,

$$
y=\left\{\begin{array}{l}
1 \text { if } y \mathfrak{i} * \leq 0 \\
2 \text { if } 0<y \mathfrak{i} * \leq .99 \\
3 \text { if } 1 \leq y \mathfrak{i} * \leq 1.99 \\
4 \text { if } 2 \leq y \mathfrak{i} * \leq 2.99 \\
5 \text { if } 3 \leq y \mathfrak{i} * \leq 3.99 \\
6 \text { if } y \mathfrak{i} * \geq 4
\end{array}\right.
$$

\subsection{Materials (Data Description)}

This study has used a large household data collected by the World Bank in 2016. The World Bank country partnership strategy (CPS) has acknowledged Pakistan's energy sector as one of the four-priority fields for World Bank enlistment (Wakeel et al., 2016). This survey covered a sample of 8,500 households. It was conducted to collect the data about the household's demographic and socio-economic attributes: such as housing type, household size, number of rooms in the house, financial details, and composition of the household. Moreover, the survey includes questions about the information focused on the household's energy attributes, important features of the potential energy alternative, and type of energy source used in the dwelling. Hence, the survey collected the data on four thematic areas: the available energy source attributes, energy consumption patterns, economic support for energy, psychographic factors that may affect energy consumption. The sample collection was done following random stratified sampling. In this way, a higher number of households were selected from rural areas. Hence such areas are selected which expected to suffer from unmet energy demand. It resulted in a sample with a high percentage of residents from highly energy-deprived areas. Such a sampling procedure was adopted to focus on the energy-poor segment of society. It also allows understanding the access to energy scenario in the country.

The data used in this paper focused on the determinants that affect the financial decision of the consumers regarding an additional amount they can pay for alternative energy sources. Alternative energy refers to an energy source used to solve the household's energy access problem during power shortage of hours. It is an energy solution used in case of the absence of the resident's current primary source of energy and expected to fill the gap of the energy needs 
of the households. It also provides reliable energy during outages. In this survey, the electrified and unelectrified households both are inquired about the WTP for the alternative energy source. Both the grid-connected and the grid non-connected household suffers from the energy access problem. A household with a grid connection is provided limited hours of access because of the power shortages and the grid non connected households have the issue of energy access.

In this study, the respondents living in the rental houses, which comprises around $5.5 \%$ of the sample, are omitted before analysis, as the deployment of the alternative energy source is decided by the building owner. Hence, the only owner owned houses are included in the analysis. Furthermore, the data is filtered according to income distribution. The outlier observations are eliminated by discarding observation below 1st and above 99th quintiles of the income distribution. The remaining sample size for the analysis is 7,745 households. The descriptive statistics for these households are presented in Table 1, which summarizes the full sample, the residents with and without alternative energy sources separately. The table gives the socio-demographic characteristics of the residents. Among those characteristics gender, household size, housing type, rooms, the family composition of the households, level of education and occupation are included. This descriptive analysis shows that the adoption of alternative energy sources is influenced by the gender difference, housing type, and occupation of the head of the household. The impact of household size and number of rooms on the deployment of the alternative energy source is less clear in the table.

Table 1: Households Socio-demographic Factors:

\begin{tabular}{|c|c|c|c|}
\hline Variable & $\begin{array}{c}\text { Full sample } \\
\% \\
\end{array}$ & $\begin{array}{l}\text { With Alternative } \\
\%\end{array}$ & $\begin{array}{c}\text { Without Alternative } \\
\%\end{array}$ \\
\hline \multicolumn{4}{|l|}{ Gender } \\
\hline Male & 63.46 & 51.59 & 69.37 \\
\hline \multicolumn{4}{|l|}{ Household size } \\
\hline $1-3$ & 10.54 & 09.05 & 11.27 \\
\hline $4-5$ & 39.32 & 39.70 & 39.12 \\
\hline 7 or more & 50.15 & 51.24 & 49.60 \\
\hline \multicolumn{4}{|l|}{ Housing type } \\
\hline Hut & 45.78 & 34.50 & 51.40 \\
\hline One story & 45.93 & 51.67 & 43.07 \\
\hline Two story or above & 8.29 & 13.83 & 05.53 \\
\hline \multicolumn{4}{|l|}{ Room does the house have } \\
\hline Hall type & 20.17 & 09.56 & 15.24 \\
\hline 2 rooms & 39.33 & 25.29 & 45.12 \\
\hline 3 rooms & 22.68 & 27.66 & 25.61 \\
\hline 4 or more rooms & 17.81 & 37.49 & 14.02 \\
\hline \multicolumn{4}{|l|}{ Marital status of head of the household } \\
\hline Single & 12.68 & 10.80 & 13.61 \\
\hline \multicolumn{4}{|l|}{ Education of Head of household } \\
\hline Illiterate & 34.82 & 24.01 & 40.20 \\
\hline Middle & 28.96 & 27.31 & 29.78 \\
\hline Matric or intermediate & 26.61 & 33.68 & 23.09 \\
\hline Graduate & 09.61 & 15.00 & 06.92 \\
\hline \multicolumn{4}{|l|}{ Occupation of head of household } \\
\hline Unskilled worker/ Petty Trader & 41.93 & 26.30 & 53.05 \\
\hline Skilled Worker & 41.37 & 44.56 & 34.15 \\
\hline Small Businessmen/ Middle: executive, & 12.22 & 19.19 & 08.54 \\
\hline Self-employed/ Medium Businessmen & 03.65 & 07.96 & 03.66 \\
\hline Officer/ Large Businessmen & 00.83 & 01.98 & 00.61 \\
\hline
\end{tabular}


The main source of electricity is also an important feature that could affect the household's financial decision to access an alternative source of energy. In the survey, the main source of energy data was gathered for grid-connected and non-connected households. The data revealed that both grid-connected and non-connected households access alternative energy sources. Hence, in the figure 1 the grid and off-grid households are subdivided to alternative energy users and nonusers. The grid-connected uses the multiple energy sources to fulfil the energy needs during blackout hours and off-grid uses an alternative energy source to fulfil the energy requirements.

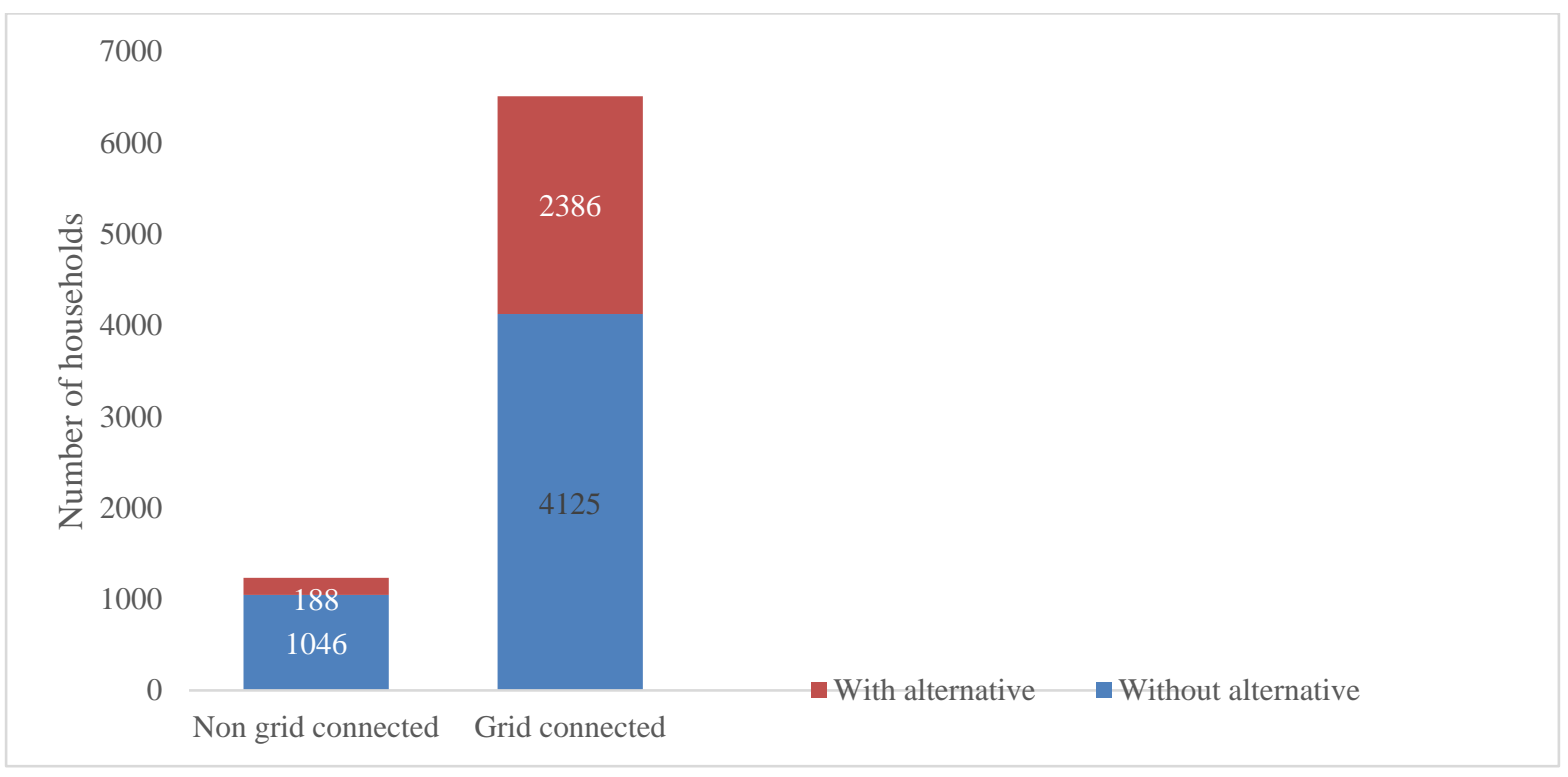

Figure 1: Connection to the grid and alternative energy source

The economic condition of households has an important impact on energy consumption and expenditure. The data about the share of energy bills in the income is often collected in several countries. The information about the household's energy expenditure provides a basis for further decision for energy alternative sources. The economic condition factors are divided into grid-connected and grid non-connected households in Figure 2. The household's average annual income amount they are willing to pay for the alternative energy and annual electricity expenditure is included. These three monetary variables are on average lower for the residence without grid-connections as compared to the grid-connected. Grid's unelectrified household's average annual income is $1693.24 \$$. It is $822.60 \$$ lesser than the grid electrified consumers average annual income. The electricity expenditure for the grid electrified is $7.25 \%$ of their average income. The grid unelectrified are spending $7.25 \%$ of their average income on electricity expenditure. On top of it, they have shown interest in paying $33 \%$ of their electricity expenditure to adopt an alternative energy source to get better electricity service. In this way, the grid unelectrified consumers are on average willing to invest $33 \%$ of their electricity expenditure to access the energy supply. The grid-connected households show better financial statistics as compared to grid non-connected. The grid-connected consumers spend on average $10.52 \%$ of their income on electricity. They are also interested in spending money $24 \%$ of their bills on alternative energy sources. In this way, the grid electrified consumers are also willing to pay for reliable energy supply. The average amount grid connected is willing to pay to avoid the outages and ensure the access to energy is lesser than the grid unconnected consumers. The grid electrified and non-electrified both types of consumers are spending a considerably high percentage of their annual average income to fulfil their energy needs. 


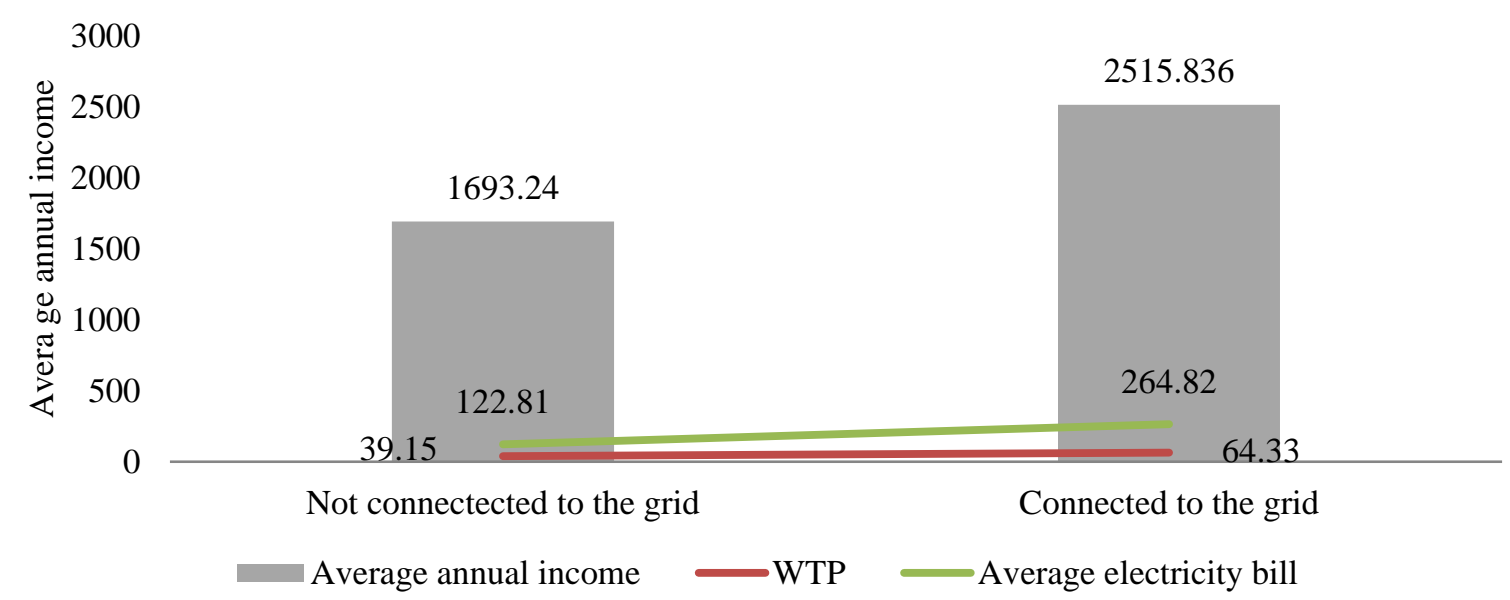

Figure 2: Income, WTP for the alternative source and electricity expenditure

Figure 3 gives information about the electrical appliances used in the household. The most commonly used electrical appliances include energy savers and fan, $73 \%$ and $81 \%$ respectively, while kitchen appliances 5\% are in bare usage. The given statistics shows that households mainly deploy electricity for cooling and lighting purpose at the residents.

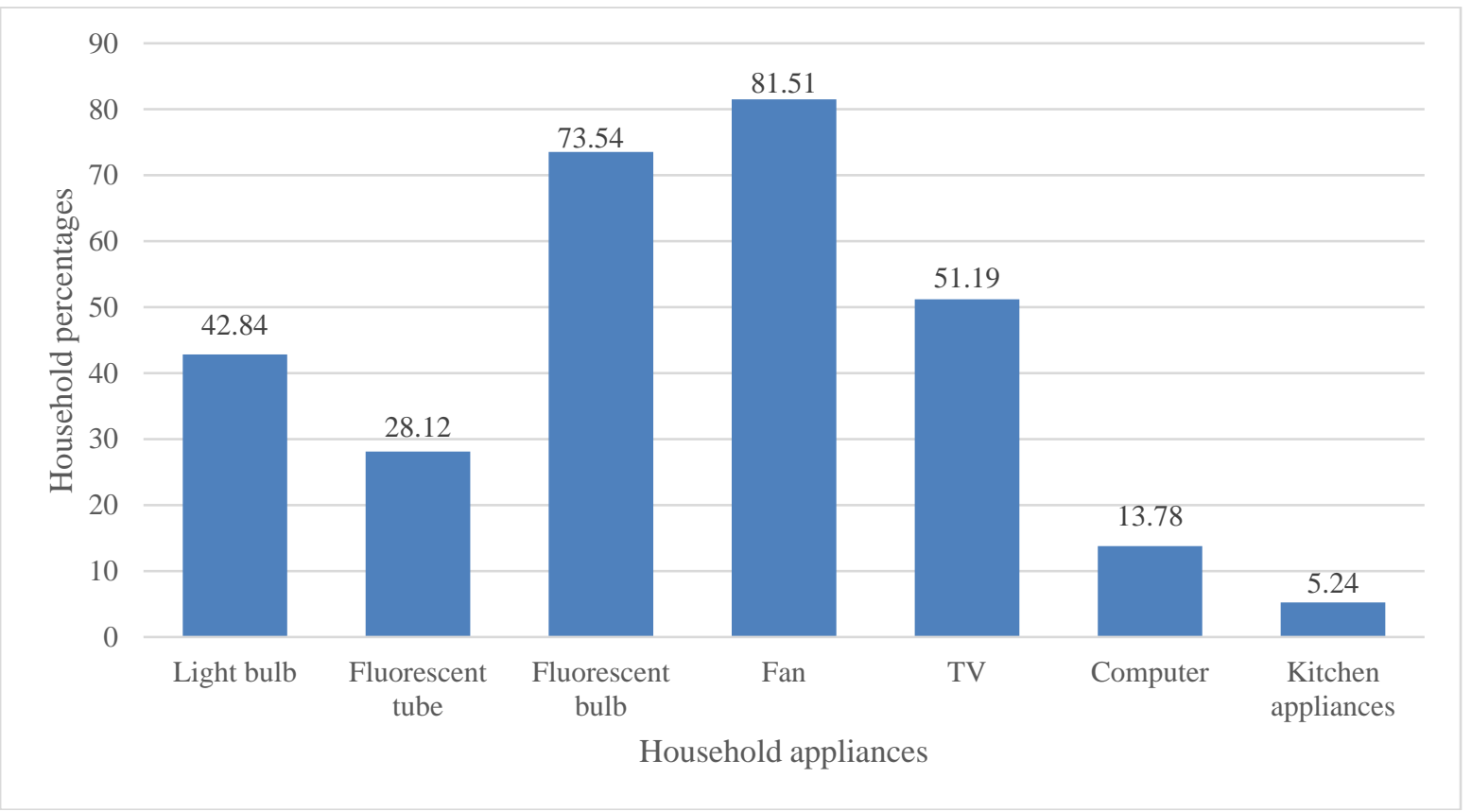

Figure 3: Main appliances used in the households

The statistics in the survey has indicated that lighting is a significant share of the household's energy consumption. The data in Figure 4 has shown the respondent's level of satisfaction regarding the current source of energy for lighting. The households have ranked their satisfaction on a scale from 1-5, respondents were requested to evaluate to what extent they were satisfied or dissatisfied with the current energy source. In the survey respondents were asked to rank their level of satisfaction forms the current source of the energy for lighting, the great majority $68 \%$ has marked it either extremely or slightly dissatisfied. Only a small amount of $10 \%$ was satisfied or extremely satisfied. 


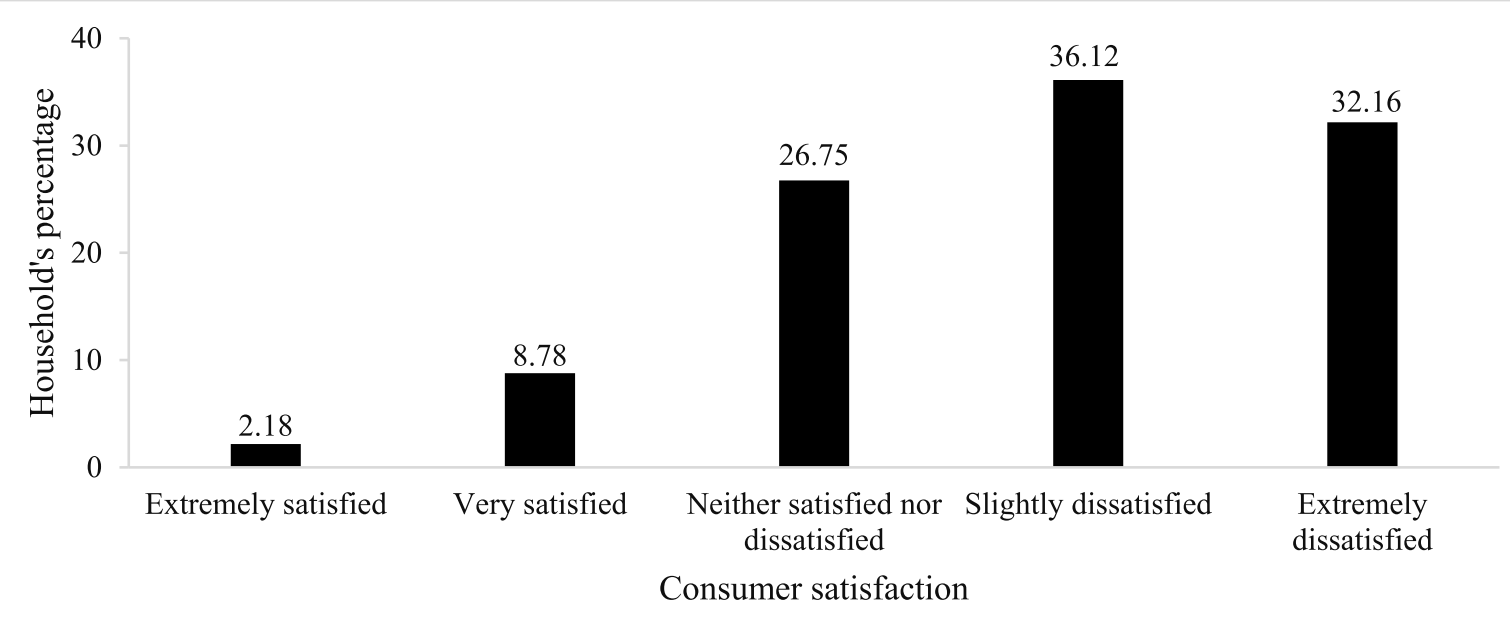

Figure 4: Satisfaction from the current source of energy for lighting

Finally, it is important to notice the consumers ranked key features of the potential energy alternative. In the survey, households have ranked the three most important features of the potential energy alternative source. Figure 5 indicates that around $82 \%$ of the respondents are interested in the improved availability of energy, whereas $74 \%$ are interested in the affordable energy source and about 64\% expressed cost saving as an important feature for the potential energy alternative. Hence, according to the survey data the most important feature is better availability, which leads to access to the electricity without any breakouts. Moreover, consumers have shown their interest in the financial issues related to the energy alternative. The possible reason is the weak financial position of households.

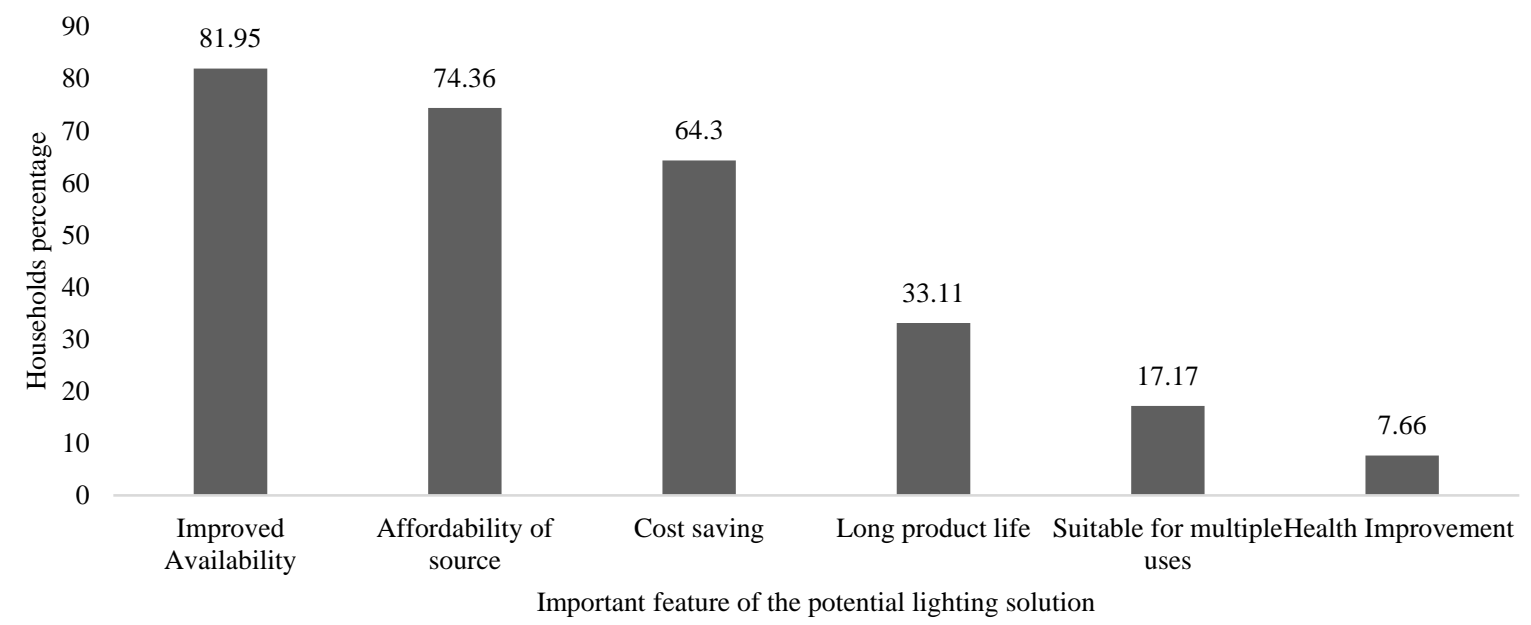

Figure 5: Most vital feature of the energy alternative

\section{Results and Discussion}

The focus of this study is to econometrically analyse the WTP for the alternative energy source of the households. The study has considered household characteristics, energy attributes, and important features of potential solutions, and type of energy source as explanatory variables. The ordered logit model estimates are given in Table 2. The data set satisfied the ordered logistic regression assumptions. The dependent variable is numerically in the form of order. 
The willingness to pay for the respondents is represented as numbers from 1 to 6 representing the amount households are willing to pay for the alternative energy source. the independent variables are categorical, ordinal, and continuous. The Wald test results and margins are given in the appendix. Several interesting results are found in the model. Table 2 model 1 gives the empirical results of the ordered logit equation estimated coefficients with respect to the households' willingness to pay for the alternative energy source. Among 25 variables included in the analysis 20 has shown significance for the WTP for the alternative energy sources. Moreover, the table 1, model 2 gives the results for the smaller sample of grid nonconnected households. The grid non connected sample is highly deprived of access to energy.

The results showed that all the household characteristics have a significant impact on the WTP decision for alternative energy source. There exists a statistically significant impact of gender difference in WTP for energy alternatives. Indeed, it is estimated that the female head of the household is willing to pay more for the improved energy alternative when compared with males. These results confirm the Bigerna \& Polinori (2015), the study which resulted from that male's willingness to pay less for the energy alternative. On the other hand, some studies (Mozumder et al., 2011; Urpelainen \& Yoon, 2015) has estimated the insignificant impact of the gender difference for the WTP for energy alternative. Theoretically, it is conceived that on average females devote a larger amount of time in the dwelling. Hence female tends to spend more money on the improved energy availability. On the other hand, on average females have less influence on the financial choice as compared to their male counterparts.

Moreover, the empirical results confirmed the statistical significance of higher education, advanced occupation, and better type of residence for the WTP for the alternative energy source. The results show that all these parameters positively determine the households WTP for the access to the energy alternative and reliable supply of energy. In addition, the size and composition of the household have a negative impact on the WTP for alternative energy. As far as economic parameter is concerned, the result indicates that increase in income is significantly associated with the households' WTP for the alternative energy source. The relevance of these household socio-economic characteristics for the WTP for the alternative energy has been recognized in the literature (Mozumder et al., 2011; Sardianou \& Genoudi, 2013; Theodoropoulou \& Karytsas, 2014; Bigerna \& Polinori, 2015; Urpelainen \& Yoon, 2015). The results also confirm the literature outcomes for household characteristics. As far as energy attributes are concerned, the empirical results showed that interest in alternatives parameters has a positive impact on the willingness to pay for energy alternatives. Furthermore, the presence of electric appliances such as energy savers, computer and television have a positive impact on households WTP for alternative energy.

In the survey, the respondents ranked the important feature they would like to have in the potential energy alternative solution which ensures the access to the energy and reliable supply of power utility. The model also included the impact of key features of potential alternatives on willingness to pay for the energy alternative source. The information about these key features is gathered from the households. It is found that financial features like affordability and cost-saving have a positive impact on the willingness to pay for energy alternatives. According to Abdullah et al. (2017) consumers have the best affordable price yardstick to buy and install the energy alternative. Moreover, the respondents who ranked improvement in health from energy alternative usage as an important feature of potential alternatives were also willing to pay more for the energy alternative. 
Table 2: Estimates of Model for WTP for Alternative Energy Source

\begin{tabular}{|c|c|c|c|c|}
\hline \multirow[t]{2}{*}{ Explanatory Variables } & \multicolumn{2}{|c|}{ Model 1} & \multicolumn{2}{|c|}{ Model 2} \\
\hline & Coeff & Std. Err & Coeff & Std. Err \\
\hline \multicolumn{5}{|l|}{ Household Characteristics } \\
\hline Gender $($ Female $=1)$ & $1.533 * * *$ & $(0.0638)$ & $0.529 * *$ & $(0.261)$ \\
\hline \multicolumn{5}{|l|}{ HH size (1-3) } \\
\hline $4-6$ & $-0.135^{*}$ & $(0.0780)$ & $0.621 * * *$ & $(0.201)$ \\
\hline 7 or above & $-0.242 * * *$ & $(0.0790)$ & -0.135 & $(0.211)$ \\
\hline \multicolumn{5}{|l|}{ Housing Type (Hut) } \\
\hline One story & $0.397 * * *$ & $(0.0600)$ & $-0.488 * *$ & $(0.198)$ \\
\hline Two story or above & $0.380 * * *$ & $(0.1020)$ & 0.596 & $(0.646)$ \\
\hline \multicolumn{5}{|l|}{ Number of Rooms (Hall type) } \\
\hline 2 Rooms & $0.630 * * *$ & $(0.0702)$ & $0.568 * * *$ & $(0.172)$ \\
\hline 3 Rooms & $1.024 * * *$ & $(0.0781)$ & $0.839 * * *$ & (0.199) \\
\hline 4 Or more rooms & $1.233 * * *$ & $(0.0886)$ & $1.060 * * *$ & $(0.252)$ \\
\hline \multicolumn{5}{|l|}{ HH Composition } \\
\hline Single parents & $-0.139 * *$ & $(0.0684)$ & $0.556^{* * *}$ & $(0.181)$ \\
\hline \multicolumn{5}{|l|}{ Education (Illiterate) } \\
\hline Primary & $0.405 * * *$ & $(0.0599)$ & -0.0830 & $(0.150)$ \\
\hline Intermediate & $0.402 * * *$ & $(0.0657)$ & -0.0604 & $(0.201)$ \\
\hline Graduate & $0.301 * * *$ & $(0.0938)$ & $0.662 * *$ & $(0.322)$ \\
\hline \multicolumn{5}{|l|}{ Occupation (Unskilled worker) } \\
\hline Skilled worker/ supervisory level & $0.446 * * *$ & $(0.0570)$ & $0.585 * * *$ & $(0.155)$ \\
\hline Small business/middle officers & $0.469 * * *$ & $(0.0771)$ & $0.657 * *$ & $(0.278)$ \\
\hline Medium business/ self employed & $0.485 * * *$ & $(0.1120)$ & 0.106 & $(0.359)$ \\
\hline Large business/ senior officers & $1.190 * * *$ & $(0.2130)$ & 1.290 & $(0.936)$ \\
\hline Income & $0.107 * * *$ & $(0.0179)$ & $0.137 * *$ & $(0.0622)$ \\
\hline \multicolumn{5}{|l|}{ Energy Situation } \\
\hline Connection to Grid & -0.131 & $(0.1290)$ & & \\
\hline Grid too far & $-0.317 * *$ & $(0.1320)$ & $-0.652 * * *$ & $(0.147)$ \\
\hline Month of Low Electricity & -0.00334 & $(0.0074)$ & & \\
\hline Energy Saver & $-0.119 * *$ & $(0.0591)$ & 0.0122 & $(0.175)$ \\
\hline Computer & $0.164 * *$ & $(0.0712)$ & -0.131 & $(0.261)$ \\
\hline Television & $0.542 * * *$ & $(0.0570)$ & $0.693 * * *$ & $(0.239)$ \\
\hline $\begin{array}{l}\text { Interest in Alternative } \\
\text { important Features for Lighting Alternative }\end{array}$ & $0.280 * * *$ & $(0.0585)$ & -0.0261 & $(0.181)$ \\
\hline Health & $0.226 * * *$ & $(0.0854)$ & $-1.035 * * *$ & $(0.342)$ \\
\hline Availability & 0.0565 & $(0.0584)$ & $0.391 * *$ & $(0.175)$ \\
\hline Affordability & $0.242 * * *$ & $(0.0522)$ & $0.719 * * *$ & $(0.189)$ \\
\hline Cost saving & $0.215 * * *$ & $(0.0473)$ & $0.388 * *$ & $(0.151)$ \\
\hline \multicolumn{5}{|l|}{ Lighting Energy Source in the HH } \\
\hline Local Mini Grid & $0.282 * * *$ & $(0.0972)$ & $0.292 *$ & $(0.161)$ \\
\hline Generator & 0.0539 & $(0.0943)$ & 0.276 & $(0.313)$ \\
\hline Solar & $0.495 * * *$ & $(0.0828)$ & $1.364 * * *$ & $(0.217)$ \\
\hline Rechargeable Batteries & $0.160 * * *$ & $(0.0526)$ & $0.388 * *$ & $(0.168)$ \\
\hline \multicolumn{5}{|l|}{ Solar Awareness } \\
\hline Know About Solar & -0.0126 & $(0.0532)$ & -0.0571 & $(0.152)$ \\
\hline Peers effect & $0.280 * * *$ & $(0.0544)$ & -0.247 & $(0.164)$ \\
\hline Constant cut 1 & -0.0397 & $(0.159)$ & 0.152 & $(0.333)$ \\
\hline Constant cut 2 & $3.248 * * *$ & $(0.164)$ & $3.734 * * *$ & $(0.357)$ \\
\hline Constant cut 3 & $5.135 * * *$ & $(0.171)$ & $5.715 * * *$ & $(0.385)$ \\
\hline Constant cut 4 & $6.450 * * *$ & $(0.177)$ & $6.625 * * *$ & $(0.415)$ \\
\hline Constant cut5 & $7.534 * * *$ & $(0.185)$ & $7.061 * * *$ & $(0.438)$ \\
\hline Observations & 7,745 & & 1,163 & \\
\hline
\end{tabular}


Hence the results confirm health improvement, affordability, and cost-saving as key features for determining the WTP for energy alternatives. They have a positive impact on WTP for energy alternatives. This is probably due to the incentive behind the adoption of an energy source alternate. In the case of developing countries like Pakistan, the alternative energy source is deployed to fulfil the energy requirement rather than the deployment of the new technology or climate protection. Households adopt alternative energy sources due to under electrification and they might consider the cost due to the financial constraints. In an earlier study Graber, Narayannan, Alfaro, and Palit, (2018) documented the power, cost, and reliability as the factor affecting the household's choice of energy.

The estimation of factors affecting the WTP for the alternative energy source may differ based on the grid connection status. Hence, the model is estimated again by using data of a small sample only from grid non-connected households. The results are given in Table 2 Model 2. The explanatory factors are the same. As the table shows almost all the main results remain unchanged in case of Model 1. The only significant difference in the outcomes is the availability of energy as an important feature for energy alternatives is no more insignificant. This outcome applies that in the case of non-grid connected households, the availability of energy alternatives would have a positive impact on WTP for the energy alternative source. Hence, the household deprived of the grid connection has shown interest to make a financial investment for the access of energy.

\section{Conclusion}

Pakistan is facing a relentless energy shortage. Due to the high cost of energy generation mega projects and a weaker economy, it is important to understand and estimate the part of the burden that could be shifted to the public to solve the energy access problem. This paper has focused on the factor affecting the households WTP for the alternative energy source. An ordered logit model is estimated to explore the factor that is responsible for the willingness to pay for an energy alternative solution. The results showed the importance of household attributes, access to electric appliances and the type of energy sources in determining the willingness to pay for alternative energy. Moreover, the paper also found the significance of features of potential lighting alternatives which affect the households WTP for alternative energy. These features include health, affordability, and cost-saving.

The study implies that households are sensitive to the expenditure on the energy alternative. The possible reason is the households' weak financial position and a substantial burden of energy expenditure. The study renders the consumers the financial value of reliable supply and access to energy. The results are helpful to target the consumers that could take part in the investment for the alternative way to access the energy. One suggestion is that the government needs to enhance the research for affordable, and cost-saving energy alternatives. Furthermore, there is a need for more research in the field of cost-saving and affordable alternative energy sources. The poor household may not have the capacity to finance the energy alternative source, in this regard the government subsidy may be helpful for them and it is also important to developing cheap energy alternatives. One suggestion is the financial assistance in the form of easily accessible loans, subsidies, and attractive instalments for the energy products. The findings also find relevance for the health safe energy alternative products. It is essential to introduce such policies which ensure the health standards of energy alternative products. The empirical analysis also sheds light on the importance of peers' effect in the WTP for an 
alternative. This paper is useful to the policymaker in designing such energy policies that enhance public participation to finance the energy provision.

\section{References}

Abdullah., Zhou, D., Shah, T., Jebran, K., Ali, S., Ali, A., \& Ali, A. (2017). Acceptance and willingness to pay for solar home system: Survey evidence from northern area of Pakistan. Energy Reports, 3, 54-60. http://dx.doi.org/10.1016/j.egyr.2017.03.002

Alternative Energy Development Board. (2018). Progress so far made in solar power sector in Pakistan. http://www.aedb.org/ae-technologies/solar-power/solar-current-status

Bigerna, S., \& Polinori, P. (2015). Assessing the Determinants of Renewable Electricity Acceptance Integrating Meta-Analysis Regression and a Local Comprehensive Survey. Sustainability. 7, 11909-11932. http://www.mdpi.com/2071-1050/7/9/11909

Borchers, M. A., Duke, M. Joshua., \& Parsons, R. George. (2007). Does willingness to pay for green energy differ by source? Energy policy. 35, 3327-3334

Friebe, C.A., Flotow, P. V., \& Täube, F.A. (2013). Exploring the link between products and services in low-income markets: Evidence from solar home systems. Energy Policy, 52, 760-769. http://linkinghub.elsevier.com/retrieve/pii/S0301421512009196

Gitone, I. (2014). Determinants of Adoption of Renewable Energy in Kenya. University of Nairobi.

Goverment of Pakistan. (2013). National Power Policy 2013 Intergovernmental Panel on Climate Change (ed.), Cambridge University Press. http://www.ppib.gov.pk/National Power Policy 2013.pdf

Graber, S., Narayanan, T., Alfaro, J., \& Palit, D. (2018). Solar microgrids in rural India: Consumers' willingness to pay for attributes of electricity. Energy Sustainable Development 42, 32-43.

International Energy Agency. (2015) Pakistan: Renewables and waste for 2015. https://www.iea.org/statistics/statisticssearch/report/?country=Pakistan\&product=Re newablesandWaste

International Finance Corporation. (2017). Pakistan Off-Grid Lighting Consumer Perceptions Study

Overview. https://www.ifc.org/wps/wcm/connect/d72aa0004886746d8388f7299ede9589/Pakis tan+Solar+Consumer+Study+Overview_26thMay2015_LQ.pdf?MOD=AJPERES

Ministry of Finance. (2014). Energy. http://www.finance.gov.pk/survey/chapter_12/14energy.pdf

Mozumder, P., Vásquez, W.F. \& Marathe, A. (2011). Consumers' preference for renewable energy in the southwest USA. Energy Economics, 33, 1119-1126. http://dx.doi.org/10.1016/j.eneco.2011.08.003

National Renewable Energy Laboratory. (NREL). (2014). Pakistan Resource Maps. http://www.nrel.gov/international/ra_pakistan.html

Rafique, M. M. \&Rehman, S. (2017). National energy scenario of Pakistan- Current status, future alternatives, and institutional infrastructure: An overview. Renewable and Sustainable Energy Review, 69, 156-167

Samad, H., Khandker, S., Asaduzzaman, M. \& Yunus, M. (2013). The benefits of solar home systems: an analysis from Bangladesh. World Bank Policy Research Working Paper.

Sardianou, E., \& Genoudi, P. (2013). Which factors affect the willingness of consumers to adopt renewable energies? Renewable Energy, 57, 1-4. http://dx.doi.org/10.1016/j.renene.2013.01.031 
Scarpa, R., \&Willis, K. (2010). Willingness-to-pay for renewable energy: Primary and discretionary choice of british households for micro-generation technologies. Energy Economics, 32, 129-136

Sheikh, M.A. (2010). Energy and renewable energy scenario of Pakistan. Renew. Sustainable Energy Review, 14, 354-363. http://linkinghub.elsevier.com/retrieve/pii/S1364032109001865

Sher, F., Abbas, A., \& Awan, R.U. (2014). An Investigation of Multidimensional Energy Poverty in Pakistan: A Province Level Analysis. Int. J. Energy Economic Policy. 52(4), 405-419.

Shi, L., Zhou, W., \& Kristrom, B. (2013). Residental demand for green electricity. Environmental Economics, 4, 1-9.

Smith, M.G., \& Urpelainen, J. (2014). Early Adopters of Solar Panels in Developing Countries: Evidence from Tanzania. Review Policy Research, 31, 17-37. http://doi.wiley.com/10.1111/ropr.12061

Theodoropoulou, H., \& Karytsas, S. (2015). Public awareness and willingness to adopt ground source heat pump for domestic heating and cooling. Renewable and Sustainable Energy Reviews, 34, 49-57.

Urpelainen, J., \& Yoon, S. (2015). Solar home systems for rural India: Survey evidence on awareness and willingness to pay from Uttar Pradesh. Energy Sustainable Developoment, $\quad 24, \quad 70-78$. http://linkinghub.elsevier.com/retrieve/pii/S0973082614001045

Wakeel, M., Chen, B., \& Jahangir, S. (2016). Overview of Energy Portfolio in Pakistan. Energy Procedia, 88 , http://linkinghub.elsevier.com/retrieve/pii/S1876610216300881 


\section{$\underline{\text { Appendix }}$}

\section{Wald Test Results}

$$
\mathrm{Chi}^{2}(34)=511.16 \text { Prob }>\mathrm{Chi}^{2}=0.0000
$$

\section{$\underline{\text { Average Marginal Affects }}$}

1._predict : $\operatorname{Pr}(\mathrm{ES} 20==1)$, predict(pr outcome $(1))$

2._predict $: \operatorname{Pr}(\mathrm{ES} 20==2)$, predict $($ pr outcome $(2))$

3._predict : $\operatorname{Pr}(\mathrm{ES} 20==3)$, predict(proutcome (3))

4._predict : $\operatorname{Pr}(\mathrm{ES} 20==4)$, predict(proutcome (4))

5._predict $: \operatorname{Pr}(\mathrm{ES} 20==5), \operatorname{predict}(\operatorname{pr}$ outcome (5))

6._predict $: \operatorname{Pr}(\mathrm{ES} 20==6)$, predict $(\operatorname{pr}$ outcome $(6))$

\begin{tabular}{|c|c|c|c|c|c|c|c|c|c|}
\hline Gender & & & & & Computer & & & & \\
\hline Predict & $\begin{array}{l}\mathrm{Dy} / \mathrm{dx} \\
\end{array}$ & Std. error & $\mathrm{z}$ & $\mathrm{P}>\mathrm{Z}$ & _predict & & & & \\
\hline 1 & -.1137073 & .0063418 & -17.93 & 0.000 & 1 & -.0142579 & .005356 & -2.66 & 0.008 \\
\hline 2 & -.129287 & .0065195 & -19.83 & 0.000 & 2 & -.0162114 & .0060789 & -2.67 & 0.008 \\
\hline 3 & .0766613 & .0039163 & 19.57 & 0.000 & 3 & .0096126 & .0036233 & 2.65 & 0.008 \\
\hline 4 & .0768807 & .0041544 & 18.51 & 0.000 & 4 & .0096401 & .0036127 & 2.67 & 0.008 \\
\hline 5 & .0487321 & .0032633 & 14.93 & 0.000 & 5 & .0061106 & .0022984 & 2.66 & 0.008 \\
\hline 6 & .0407202 & .003069 & 13.27 & 0.000 & 6 & .005106 & .0019324 & 2.64 & 0.008 \\
\hline 2. $\mathrm{HH}$ size & & & & & $\mathrm{Tv}$ & & & & \\
\hline _predict & & & & & _predict & & & & \\
\hline 1 & .0091966 & .0053986 & 1.70 & 0.088 & 1 & -.0464139 & .0043533 & $\overline{1}-66$ & 0.000 \\
\hline 2 & .0118734 & .0072917 & 1.63 & 0.103 & 2 & -.0527734 & .0048532 & 10.87 & 0.000 \\
\hline 3 & -.0062606 & .0036841 & -1.70 & 0.089 & 3 & .0312922 & .0028334 & 11.04 & 0.000 \\
\hline 4 & -.006553 & .003921 & -1.67 & 0.095 & 4 & .0313817 & .0029666 & 10.58 & 0.000 \\
\hline 5 & -.0043985 & .0026917 & -1.63 & 0.102 & 5 & .0198918 & .0020212 & 9.84 & 0.000 \\
\hline 6 & -.003858 & .002408 & -1.60 & 0.109 & 6 & .0166215 & .00178 & 9.34 & 0.000 \\
\hline 3. HH size & & & & & $\begin{array}{l}\text { Month of Low } \\
\text { Electricity }\end{array}$ & & & & \\
\hline _predict & & & & & _predict & & & & \\
\hline 1 & .0175767 & .0055537 & 3.16 & 0.002 & 1 & -.0004608 & .0005529 & -0.83 & 0.405 \\
\hline 2 & .0211106 & .007265 & 2.91 & 0.004 & 2 & -.0005239 & .0006287 & -0.83 & 0.405 \\
\hline 3 & -.0118306 & .0037486 & -3.16 & 0.002 & 3 & .0003107 & .000373 & 0.83 & 0.405 \\
\hline 4 & -.0121098 & .0039596 & -3.06 & 0.002 & 4 & .0003116 & .0003738 & 0.83 & 0.405 \\
\hline 5 & -.0079293 & .0027182 & -2.92 & 0.004 & 5 & .0001975 & .000237 & 0.83 & 0.405 \\
\hline 6 & -.0068177 & .0024342 & -2.80 & 0.005 & 6 & .000165 & .0001982 & 0.83 & 0.405 \\
\hline 2. Rooms & & & & & $\begin{array}{l}\text { Interest in } \\
\text { Alternative }\end{array}$ & & & & \\
\hline _predict & & & & & _predict & & & & \\
\hline 1 & -.0614684 & .0070537 & -8.71 & 0.000 & 1 & -.0287847 & .004556 & -6.32 & 0.000 \\
\hline 2 & -.0470342 & .0048831 & -9.63 & 0.000 & 2 & -.0327286 & .005209 & -6.28 & 0.000 \\
\hline 3 & .049879 & .0058547 & 8.52 & 0.000 & 3 & .0194066 & .0031321 & 6.20 & 0.000 \\
\hline 4 & .0341086 & .0035547 & 9.60 & 0.000 & 4 & .0194621 & .0030804 & 6.32 & 0.000 \\
\hline 5 & .014841 & .0016264 & 9.12 & 0.000 & 5 & .0123364 & .0019925 & 6.19 & 0.000 \\
\hline 6 & .009674 & .0011384 & 8.50 & 0.000 & 6 & .0103082 & .0017107 & 6.03 & 0.000 \\
\hline 3. Rooms & & & & & Health & & & & \\
\hline _predict & & & & & predict & & & & \\
\hline 1 & -.0882257 & .0071009 & -12.42 & 0.000 & 1 & -.0181322 & .0064665 & -2.80 & 0.005 \\
\hline 2 & -.091945 & .00737 & -12.48 & 0.000 & 2 & -.0206166 & .007348 & -2.81 & 0.005 \\
\hline 3 & .0752361 & .0066404 & 11.33 & 0.000 & 3 & .0122247 & .0043377 & 2.82 & 0.005 \\
\hline 4 & .0580194 & .0043771 & 13.26 & 0.000 & 4 & .0122597 & .0043844 & 2.80 & 0.005 \\
\hline 5 & .0277191 & .0022627 & 12.25 & 0.000 & 5 & .007771 & .0027931 & 2.78 & 0.005 \\
\hline 6 & .019196 & .001754 & 10.94 & 0.000 & 6 & .0064934 & .0023419 & 2.77 & 0.006 \\
\hline 4.Rooms & & & & & Availability & & & & \\
\hline _predict & & & & & _predict & & & & \\
\hline 1 & -.0992408 & .0073099 & -13.58 & 0.000 & 1 & -.0038525 & .0044169 & -0.87 & 0.383 \\
\hline 2 & -.1188156 & .0098505 & -12.06 & 0.000 & 2 & -.0043803 & .0050193 & -0.87 & 0.383 \\
\hline
\end{tabular}


M. Ifat, B. A. Mercangoz \& H. Hui

\begin{tabular}{|c|c|c|c|c|c|c|c|c|c|}
\hline 3 & .0861586 & .0073323 & 11.75 & 0.000 & 3 & .0025973 & .0029745 & 0.87 & 0.383 \\
\hline 4 & .0707175 & .0053721 & 13.16 & 0.000 & 4 & .0026048 & .0029878 & 0.87 & 0.383 \\
\hline 5 & .0355823 & .0027998 & 12.71 & 0.000 & 5 & .0016511 & .0018937 & 0.87 & 0.383 \\
\hline 6 & .0255982 & .0021483 & 11.92 & 0.000 & 6 & .0013796 & .001583 & 0.87 & 0.383 \\
\hline HH Composition & & & & & Affordability & & & & \\
\hline _predict & & & & & _predict & & & & \\
\hline 1 & .0116514 & .0051864 & 2.25 & 0.025 & 1 & -.0190848 & .0039687 & -4.81 & 0.000 \\
\hline 2 & .0132478 & .0058834 & 2.25 & 0.024 & 2 & -.0216997 & .0045265 & -4.79 & 0.000 \\
\hline 3 & -.0078553 & .0035029 & -2.24 & 0.025 & 3 & .012867 & .002665 & 4.83 & 0.000 \\
\hline 4 & -.0078778 & .0034991 & -2.25 & 0.024 & 4 & .0129038 & .002707 & 4.77 & 0.000 \\
\hline 5 & -.0049935 & .0022252 & -2.24 & 0.025 & 5 & .0081793 & .0017349 & 4.71 & 0.000 \\
\hline 6 & -.0041725 & .0018647 & -2.24 & 0.025 & 6 & .0068346 & .0014645 & 4.67 & 0.000 \\
\hline HH Head Edu & & & & & Cost Saving & & & & \\
\hline _predict & & & & & _predict & & & & \\
\hline 1 & -.032531 & .0045174 & -7.20 & 0.000 & 1 & -.0171978 & .0035861 & -4.80 & 0.000 \\
\hline 2 & -.0382787 & .0056825 & -6.74 & 0.000 & 2 & -.0195541 & .0040933 & -4.78 & 0.000 \\
\hline 3 & .0244543 & .0036794 & 6.65 & 0.000 & 3 & .0115947 & .0024322 & 4.77 & 0.000 \\
\hline 4 & .0228014 & .0033011 & 6.91 & 0.000 & 4 & .0116279 & .0024342 & 4.78 & 0.000 \\
\hline 5 & .0131932 & .0019088 & 6.91 & 0.000 & 5 & .0073705 & .0015605 & 4.72 & 0.000 \\
\hline 6 & .0103609 & .0015359 & 6.75 & 0.000 & 6 & .0061588 & .0013213 & 4.66 & 0.000 \\
\hline 3. HH Head Edu & & & & & $\begin{array}{l}\text { Agriculture } \\
\text { And Livestock }\end{array}$ & & & & \\
\hline _predict & & & & & _predict & & & & \\
\hline 1 & -.0324737 & .0048741 & -6.66 & 0.000 & 1 & .000353 & .0050815 & 0.07 & 0.945 \\
\hline 2 & -.0381889 & .006447 & -5.92 & 0.000 & 2 & .0004014 & .0057773 & 0.07 & 0.945 \\
\hline 3 & .0244089 & .0040758 & 5.99 & 0.000 & 3 & -.000238 & .0034255 & $\begin{array}{l}-0.07 \\
\end{array}$ & 0.945 \\
\hline 4 & .0227545 & .0036898 & 6.17 & 0.000 & 4 & -.0002387 & .0034356 & -0.07 & 0.945 \\
\hline 5 & .0131634 & .0020875 & 6.31 & 0.000 & 5 & -.0001513 & .0021778 & -0.07 & 0.945 \\
\hline 6 & .0103358 & .0016297 & 6.34 & 0.000 & 6 & -.0001264 & .0018197 & -0.07 & 0.945 \\
\hline & & & & & & & & & \\
\hline 4. HH Head Edu & & & & & $\begin{array}{l}\text { Local Mini } \\
\text { Grid }\end{array}$ & & & & \\
\hline _predict & & & & & _predict & & & & \\
\hline 1 & -.0268334 & .0068531 & -3.92 & 0.000 & 1 & -.0153418 & .0073925 & -2.08 & 0.038 \\
\hline 2 & -.0298124 & .0090088 & -3.31 & 0.001 & 2 & -.0174438 & .0084134 & -2.07 & 0.038 \\
\hline 3 & .0199843 & .005495 & 3.64 & 0.000 & 3 & .0103434 & .0049762 & 2.08 & 0.038 \\
\hline 4 & .0182729 & .0051433 & 3.55 & 0.000 & 4 & .010373 & .0050108 & 2.07 & 0.038 \\
\hline 5 & .0103687 & .0029757 & 3.48 & 0.000 & 5 & .0065751 & .0031824 & 2.07 & 0.039 \\
\hline 6 & .0080199 & .00232 & 3.46 & 0.001 & 6 & .0054941 & .0026633 & 2.06 & 0.039 \\
\hline 2. HH Head Occ & & & & & Generator & & & & \\
\hline _predict & & & & & _predict & & & & \\
\hline 1 & -.0383302 & .0043174 & $\begin{array}{l}-8.88 \\
\end{array}$ & 0.000 & 1 & -.0027991 & .0071058 & -0.39 & 0.694 \\
\hline 2 & -.0466326 & .0056366 & -8.27 & 0.000 & 2 & -.0031827 & .0080811 & -0.39 & 0.694 \\
\hline 3 & .0308534 & .003892 & 7.93 & 0.000 & 3 & .0018872 & .0047958 & 0.39 & 0.694 \\
\hline 4 & .0275404 & .0032609 & 8.45 & 0.000 & 4 & .0018926 & .0048024 & 0.39 & 0.694 \\
\hline 5 & .0151788 & .0017606 & 8.62 & 0.000 & 5 & .0011996 & .0030444 & 0.39 & 0.694 \\
\hline 6 & .0113902 & .0013457 & 8.46 & 0.000 & 6 & .0010024 & .0025451 & 0.39 & 0.694 \\
\hline & & & & & & & & & \\
\hline 3. HH Head Occ & & & & & Solar & & & & \\
\hline _predict & & & & & _predict & & & & \\
\hline 1 & -.0410852 & .0054123 & -7.59 & 0.000 & 1 & -.0352369 & .0062927 & -5.60 & 0.000 \\
\hline 2 & -.0514679 & .0084647 & -6.08 & 0.000 & 2 & -.0400649 & .0071512 & -5.60 & 0.000 \\
\hline 3 & .0332352 & .0050449 & 6.59 & 0.000 & 3 & .0237567 & .0042246 & 5.62 & 0.000 \\
\hline 4 & .0299857 & .0045336 & 6.61 & 0.000 & 4 & .0238247 & .0042793 & 5.57 & 0.000 \\
\hline 5 & .0167001 & .0025441 & 6.56 & 0.000 & 5 & .0151017 & .0027498 & 5.49 & 0.000 \\
\hline 6 & .0126322 & .0019758 & 6.39 & 0.000 & 6 & .0126189 & .0023538 & 5.36 & 0.000 \\
\hline 4. HH Head Occ & & & & & $\begin{array}{l}\text { Rechargeable } \\
\text { Batteries }\end{array}$ & & & & \\
\hline _predict & & & & & _predict & & & & \\
\hline 1 & -.0430517 & .0071711 & -6.00 & 0.000 & 1 & -.0102256 & .0039708 & -2.58 & 0.010 \\
\hline 2 & -.0550842 & .012379 & -4.45 & 0.000 & 2 & -.0116267 & .0045157 & -2.57 & 0.010 \\
\hline 3 & .0349478 & .0065127 & 5.37 & 0.000 & 3 & .0068941 & .002679 & 2.57 & 0.010 \\
\hline 4 & .0317797 & .0063533 & 5.00 & 0.000 & 4 & .0069138 & .0026857 & 2.57 & 0.010 \\
\hline 5 & .017836 & .00382 & 4.67 & 0.000 & 5 & .0043824 & .0017103 & 2.56 & 0.010 \\
\hline 6 & .0135724 & .0030716 & 4.42 & 0.000 & 6 & .0036619 & .0014336 & 2.55 & 0.011 \\
\hline 5. HH Head Occ & & & & & $\begin{array}{ll}\text { Know about } \\
\text { Solar }\end{array}$ & & & & \\
\hline _predict & & & & & _predict & & & & \\
\hline
\end{tabular}


Consumer Willingness to Pay for the Alternative Energy Sources in Pakistan

\begin{tabular}{|c|c|c|c|c|c|c|c|c|c|}
\hline 1 & -.0756733 & .0081708 & -9.26 & 0.000 & 1 & -.0155316 & .0045845 & -3.39 & 0.001 \\
\hline 2 & -.1444492 & .0294173 & -4.91 & 0.000 & 2 & -.0176597 & .0052037 & -3.39 & 0.001 \\
\hline 3 & .0634929 & .0070102 & 9.06 & 0.000 & 3 & .0104714 & .0030874 & 3.39 & 0.001 \\
\hline 4 & .0694976 & .0114539 & 6.07 & 0.000 & 4 & .0105013 & .0031031 & 3.38 & 0.001 \\
\hline 5 & .0460698 & .0095272 & 4.84 & 0.000 & 5 & .0066564 & .0019766 & 3.37 & 0.001 \\
\hline 6 & .0410621 & .0104381 & 3.93 & 0.000 & 6 & .0055621 & .0016653 & 3.34 & 0.001 \\
\hline $\begin{array}{l}\text { Connected to } \\
\text { Grid }\end{array}$ & & & & & Trust on SHS & & & & \\
\hline _predict & & & & & _predict & & & & \\
\hline 1 & .0113445 & .0096851 & 1.17 & 0.241 & 1 & .0343379 & .004848 & 7.08 & 0.000 \\
\hline 2 & .0128989 & .0110187 & 1.17 & 0.242 & 2 & .0390427 & .0054957 & 7.10 & 0.000 \\
\hline 3 & -.0076485 & .0065346 & -1.17 & 0.242 & 3 & -.0231506 & .0032824 & -7.05 & 0.000 \\
\hline 4 & -.0076704 & .0065474 & -1.17 & 0.241 & 4 & -.0232168 & .0032791 & -7.08 & 0.000 \\
\hline 5 & -.004862 & .0041559 & -1.17 & 0.242 & 5 & -.0147163 & .0021362 & -6.89 & 0.000 \\
\hline 6 & -.0040626 & .0034771 & -1.17 & 0.243 & 6 & -.0122969 & .0018468 & -6.66 & 0.000 \\
\hline Grid too Far & & & & & Peers Effect & & & & \\
\hline _predict & & & & & _predict & & & & \\
\hline 1 & .022934 & .0099259 & 2.31 & 0.021 & 1 & -.0262038 & .0042297 & -6.20 & 0.000 \\
\hline 2 & .0260763 & .0113171 & 2.30 & 0.021 & 2 & -.0297941 & .0048252 & -6.17 & 0.000 \\
\hline 3 & -.0154621 & .0067026 & -2.31 & 0.021 & 3 & .0176666 & .0028371 & 6.23 & 0.000 \\
\hline 4 & -.0155063 & .0067232 & -2.31 & 0.021 & 4 & .0177171 & .0028886 & 6.13 & 0.000 \\
\hline 5 & -.0098289 & .0042761 & -2.30 & 0.022 & 5 & .0112303 & .0018664 & 6.02 & 0.000 \\
\hline 6 & -.008213 & .0035857 & -2.29 & 0.022 & 6 & .009384 & .0015966 & 5.88 & 0.000 \\
\hline Energy Saver & & & & & Income & & & & \\
\hline _predict & & & & & _predict & & & & \\
\hline 1 & .003785 & .0044237 & 0.86 & 0.392 & 1 & -.0081408 & .0013709 & -5.94 & 0.000 \\
\hline 2 & .0043036 & .0050256 & 0.86 & 0.392 & 2 & -.0092562 & .0015367 & -6.02 & 0.000 \\
\hline 3 & -.0025518 & .0029805 & -0.86 & 0.392 & 3 & .0054885 & .0009246 & 5.94 & 0.000 \\
\hline 4 & -.0025591 & .0029905 & -0.86 & 0.392 & 4 & .0055042 & .0009187 & 5.99 & 0.000 \\
\hline 5 & -.0016221 & .001896 & -0.86 & 0.392 & 5 & .0034889 & .0005944 & 5.87 & 0.000 \\
\hline 6 & -.0013554 & .001585 & -0.86 & 0.392 & 6 & .0029153 & .0005104 & 5.71 & 0.000 \\
\hline
\end{tabular}

